DOI: https://doi.org/10.47405/mjssh.v5i12.594

\begin{tabular}{|c|c|}
\hline 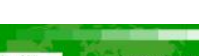 & Malaysian Journal of Social Sciences and Humanities (MJSSH) \\
\hline Malaysian Journal of & Volume 5, Issue 12, December 2020 \\
\hline (MJ-sSH) & e-ISSN : 2504-8562 \\
\hline & $\begin{array}{l}\text { Journal home page: } \\
\text { www.msocialsciences.com }\end{array}$ \\
\hline
\end{tabular}

\title{
Strategi Pembangunan Aspek Kesejahteraan Kendiri bagi Mendepani Tekanan Akademik Semasa Wabak COVID-19
}

\author{
Abdul Rashid Abdul Aziz¹, Amin Al Haadi Shafie¹, Umi Hamidaton Mohd Soffian Lee², Raja Nur \\ Syafiqah RajaAshaari1 \\ ${ }^{1}$ Fakulti Kepimpinan dan Pengurusan, Universiti Sains Islam Malaysia (USIM) \\ ${ }^{2}$ Fakulti Ekonomi \& Muamalat, Universiti Sains Islam Malaysia (USIM)
}

Correspondence: Abdul Rashid Abdul Aziz (rashid@usim.edu.my)

\begin{abstract}
Abstrak
Pandemik Coronavirus Disease 2019 (COVID-19) yang melanda Malaysia dan seluruh dunia telah memberi implikasi yang sangat besar kepada pelbagai sektor termasuklah sektor pendidikan negara. Ia menuntut setiap pelajar untuk beradaptasi dengan sistem pengajaran dan pembelajaran (PdP) secara dalam talian daripada sistem konvensional yang sedia ada. Proses adaptasi ini memerlukan pelajar untuk mempunyai strategi daya tindak yang bersesuaian agar dapat mendepani tekanan akademik yang berlaku. Justeru, kajian ini adalah bertujuan untuk meninjau cabaran pembelajaran dalam talian dalam kalangan pelajar, impak tekanan akademik terhadap kesejahteraan kendiri dan strategi daya tindak yang boleh diaplikasikan oleh pelajar. Maklumat yang diketengahkan adalah berdasarkan kajian perpustakaan melalui kaedah analisis kandungan. Teori Kesejahteraan Psikologi atau Psychological Well-being (PWB) telah diadun bersama Teori Transaksional Tekanan dan Daya Tindak Lazarus dan Folkman bagi merungkai permasalahan yang wujud ini. Dapatan kajian menunjukkan terdapat pelbagai faktor dalaman dan luaran yang menjadi cabaran kepada pembelajaran dalam talian yang memberi natijah terhadap tekanan akademik. Di Malaysia, kajian berkaitan cabaran pembelajaran dalam talian semasa norma baharu yang mencetuskan tekanan akademik masih lagi terhad dan minima. Oleh itu, kajian ini dapat menjadi satu platform dan sumber rujukan baru khususnya terhadap institusi pendidikan di negara ini bagi memastikan sistem pembelajaran dalam talian dapat dilaksanakan dengan efisien serta dimanfaatkan secara optimum oleh setiap pelajar di Malaysia.
\end{abstract}

Kata kunci: tekanan akademik, pembelajaran dalam talian, norma baharu

\section{Development Strategy of Self Well-Being to Overcome Academic Stress During COVID-19}

\begin{abstract}
Coronavirus Disease 2019 (COVID-19) pandemic which strike Malaysia and around the world caused huge implications for various sectors including education sector. It requires every student to adapt to the online teaching and learning system rather than the existing conventional system. This adaptation process requires students to have appropriate coping strategies in order to cope with the academic stress that occurred. Thus, this study aims to examine the challenges of online learning among students, the impact of academic stress on self well-being and coping strategies that can be applied. This is library research which applied content analysis methods. The Theory of Psychological Well-Being
\end{abstract}


(PWB) has been blended with Lazarus and Folkman's Transactional Theory of Stress and Coping Skills to unravel these existing problems. Findings showed that there are various internal and external factors which gave a challenge to online learning that resulted in academic stress. In Malaysia, studies related to the challenges of online learning during the new norms that trigger academic stress are still limited and minimal. Therefore, this study can be a new platform and source of reference, especially for educational institutions in the country to ensure that the online learning system can be implemented efficiently and optimally utilized by every student in Malaysia.

Keywords: academic stress, online learning, new norms

\section{Pengenalan}

Pandemik COVID-19 yang melanda Malaysia telah memberi kesan yang sangat besar kepada sistem politik, ekonomi, sosial, kesihatan dan perkhidmatan negara. Bahkan impaknya juga turut mempengaruhi sektor pendidikan negara. Menurut laporan daripada Pertubuhan Kesihatan Sedunia (World Health Organisation, WHO) sehingga 30 November 2020, jumlah kes COVID-19 mencecah 62 juta dengan lebih dari 1.4 juta kematian di seluruh dunia. Di Malaysia pula, jumlah kes positif telah mencapai angka 65,697 dan kematian sebanyak 360 orang (Laporan Statistik Kementerian Kesihatan Malaysia, 2020) sekali gus wabak yang melanda Malaysia ini telah memberi kesan yang sangat besar kepada sistem politik, ekonomi, sosial, kesihatan dan pendidikan.

Laporan WHO juga menganggarkan peningkatan kes-kes yang melibatkan kesihatan mental bagi penduduk dunia lantaran pandemik COVID-19 ini. Ekoran dari wabak yang berlaku ini, kerajaan Malaysia telah mengumumkan pelaksanaan Perintah Kawalan Pergerakan (PKP) bermula 18 Mac 2020 bertujuan untuk memutuskan rantaian wabak dengan mengawal penularan virus. Antara pelaksanaan PKP ialah penutupan semua institusi pendidikan termasuklah taska, sekolah, pusat tahfiz dan kolej. Malah, turut ditutup ialah institusi pendidikan tinggi yang melibatkan universiti awam dan swasta serta institut latihan kemahiran di seluruh negara. Krisis global akibat penularan wabak COVID-19 ini bukan sahaja menyebabkan pembelajaran dan pengajaran secara konvensional tertangguh, bahkan menjadikan tugasan para pelajar semakin mencabar apabila mereka perlu menyesuaikan diri dengan norma kehidupan dan kebiasaan baharu yang memerlukan proses Pengajaran dan Pembelajaran (PdP) dilaksanakan secara dalam talian.

Jika ditelusuri, semasa Perintah Kawalan Pergerakan (PKP) dilaksanakan, Suruhanjaya Komunikasi dan Multimedia Malaysia (SKMM) telah merekodkan peningkatan sebanyak 23.5 peratus dalam aliran trafik internet di seluruh negara pada minggu pertama PKP, dan seterusnya meningkat lagi sebanyak 8.6 peratus pada minggu kedua (SKMM, 2020). Peningkatan capaian internet ini antaranya disebabkan oleh medium pembelajaran di Malaysia telah bertukar secara drastik melalui kaedah secara dalam talian (online). Malah selain bidang pendidikan, sektor perniagaan, pembelian, perkhidmatan sehinggalah kepada pengangkutan juga menjadikan medium dalam talian sebagai platform utama. Senario ini telah mewujudkan satu norma baharu dalam kehidupan setiap individu, begitu juga dengan golongan pelajar yang majoritinya adalah terdiri daripada golongan remaja.

Aspirasi Malaysia dalam melahirkan modal insan yang mampu berdaya saing dalam pasaran ekonomi global telah dirangka dalam Pelan Pembangunan Pendidikan Malaysia selaras dengan falsafah pendidikan negara bagi melahirkan insan yang holistik dan seimbang. Revolusi industri 4.0 (IR 4.0) menggariskan inovasi sebagai elemen utama bagi melahirkan modal insan yang kompetitif dan berdaya saing dalam pasaran pekerjaan global. Bahkan teknologi maklumat dan komunikasi (Information and Communication Technology atau ICT) juga merupakan elemen penting bagi memastikan golongan muda di Malaysia cakna dengan keperluan pasaran pekerjaan masa kini. Justeru, pembelajaran dalam talian ini adalah satu anjakan yang digariskan dalam Pelan Pembangunan Pendidikan Malaysia 20152025 di mana kerajaan melalui Kementerian Pelajaran Malaysia telah pun menggariskan 10 lonjakan yang perlu dicapai dalam mendorong kecemerlangan berterusan sistem pendidikan tinggi. Bahkan, pembelajaran dalam talian tahap global merupakan salah satu dari lonjakan tersebut. Hal ini bagi memastikan graduan yang lahir hasil dari 'pacuan' nilai tambah sejak di pusat pengajian tinggi dapat 
mencapai aspirasi, keberhasilan dan kecekapan dalam mendepani persekitaran global yang berubah dan mencabar.

Pengajaran dan Pembelajaran (PdP) dalam talian menerusi platform digital telah meledak beberapa dekat lalu dalam dunia pendidikan dan menjadi isu serta perbincangan banyak pihak (Reggie, 2013). Namun baru-baru ini diskusi berhubung PdP dalam talian menjadi isu hangat warga pendidik selepas bermulanya era pembelajaran norma baharu semasa COVID-19. Hal ini kerana, landskap sistem pendidikan dilihat berubah selepas wabak COVID-19 melanda penghujung 2019. Natijahnya, kebanyakan pelajar universiti mengalami kejutan disebabkan PKP yang dijalankan telah menghentikan semua kegiatan PdP bersemuka dan diganti dengan PdP secara dalam talian. Perubahan mendadak ini pastinya memerlukan proses adaptasi dan mengundang rasa bimbang dalam kalangan pelajar.

Cabaran utama PdP dalam talian ini ialah pembinaan aspek pembangunan insaniah yang bukan sahaja mementingkan aspek teori dan pembelajaran di kelas semata-mata, namun ia lebih jauh dari itu di mana elemen praktikaliti dalam aktiviti gerak-kerja dititikberatkan bagi memantapkan lagi ciri personaliti, keyakinan diri, komunikasi dan sikap para pelajar. Hal ini juga telah ditekankan oleh Presiden Kongres Kesatuan Sekerja Malaysia (MTUC), Datuk Abdul Halim Mansor, bahawa universiti sepatutnya meletakkan aspek praktikal lebih daripada teori semata-mata, di mana semua universiti di Malaysia didapati masih mempraktikkan 60 peratus teori dan 40 peratus praktikal. Sekiranya pelajar diberi peluang yang lebih lama untuk menimba pengalaman dalam gerak-kerja sebenar atau lapangan, ia akan memberi pendedahan awal kepada mereka dengan elemen, suasana dan persekitaran di tempat kerja.

Masalah kesihatan mental wujud dalam semua peringkat lapisan masyarakat dan ia perlu ditangani secara bersama. Tekanan akademik didefinisikan sebagai keadaan yang tidak menggembirakan rentetan daripada tuntutan yang perlu dipenuhi oleh pelajar sekali gus mencetuskan kebimbangan dan mempengaruhi kesejahteraan dalam pengajiannya (Mohd Arif \& Saodah, 2019). Le, Berenbaum dan Raghavan (2002) mendapati bahawa pelajar institusi pengajian tinggi yang berada di bandar-bandar besar di Malaysia mencatat tahap alexithymia yang tinggi. Alexithymia dapat dikesan dalam kalangan pelajar, misalnya sukar memahami, memproses dan menzahirkan emosi dengan baik dan ini boleh menjadi penyebab kepada masalah psikiatri yang lain (Howell et al., 2012). Selain itu, menahan dan memendam emosi juga akan menyebabkan masalah psikologi dan membawa kepada masalah kesihatan fizikal seseorang (King \& Pennebaker, 1998). Justeru, penulisan artikel ini adalah bertujuan untuk melihat tekanan akademik semasa wabak COVID-19 dan solusi melalui pembangunan aspek kesejahteraan kendiri dalam mendepani isu tekanan akademik.

\section{Sorotan Literatur}

Pembelajaran dalam talian merupakan sesuatu yang tidak asing lagi pada saat ini. Hampir semua peringkat pembelajaran sama ada di peringkat rendah sehingga ke pusat pengajian tinggi mula memanfaatkan pembelajaran dalam talian sebagai salah satu norma baharu untuk dipraktikkan. Malahan ia merupakan satu transformasi untuk meletakkan sistem pendidikan di Malaysia sebagai salah satu hab pendidikan pada tahap global (Kementerian Pengajian Tinggi, 2011). Sejajar dengan itu, beberapa langkah drastik telah dibuat dan ia sedikit sebanyak telah memberi impak kepada sikap individu yang merujuk kepada golongan pelajar. Proses pembelajaran dalam talian telah diteruskan melalui beberapa pengubahsuaian untuk mengoptimumkan impak dan kesannya kepada pelajar sama ada melibatkan bentuk komunikasi segerak dan tidak segerak (Mohamed Nazul, 2020). Namun begitu, ia dikaitkan dengan tekanan akademik dalam kalangan pelajar rentetan daripada perubahan gaya pembelajaran secara mendadak ini.

Tekanan akademik didefinisikan sebagai keadaan yang tidak menggembirakan rentetan daripada tuntutan yang perlu dipenuhi oleh pelajar sekali gus mencetuskan kebimbangan dan mempengaruhi kesejahteraan dalam pengajiannya (Mohd Arif \& Saodah, 2019). Tekanan akademik yang dialami oleh pelajar kebanyakannya datang dari pelbagai tuntutan di universiti. Terdapat empat jenis sumber tekanan akademik yang kerap berlaku dalam kalangan pelajar termasuklah tuntutan fizikal (physical demand), tuntutan tugas (task demand), tuntutan peranan (role demand) dan tuntutan interpersonal atau 
interpersonal demand (Desmita, 2009). Dalam kajian Sri Nurhayati dan rakan (2020) terhadap tekanan akademik, daya tindak dan adaptasi sosial dalam kalangan 424 orang responden mendapati bahawa tekanan akademik, daya tindak dan adaptasi sosial mempunyai pengaruh yang signifikan terhadap kesejahteraan psikologi pelajar.

Dalam sektor pendidikan, setelah menularnya pandemik COVID-19, kesemua sekolah termasuk institusi pengajian tinggi awam dan swasta di seluruh negara terpaksa ditutup serentak rentetan penularan wabak yang dilihat mampu memberi kesan kepada perjalanan operasi organisasi serta pengajaran dan pembelajaran bagi organisasi terlibat. Keadaan semasa pandemik COVID-19 ini memerlukan tindakan pantas dari pihak berwajib seperti pihak kerajaan, Kementerian Pengajian Tinggi dan institusi terbabit untuk membuat keputusan terbaik bagi mengelakkan jangkitan melalui perlaksanaan Perintah Kawalan Pergerakan (PKP). Oleh itu, pada 16 Mei 2020, Majlis Keselamatan Negara telah meluluskan cadangan yang dikemukakan oleh Kementerian Pengajian Tinggi (KPT) untuk mengendalikan segala aktiviti di kampus melibatkan ke semua Institusi Pengajian Tinggi (IPT) di seluruh negara (Kementerian Pengajian Tinggi, 2020).

Kaedah pembelajaran yang dilaksanakan secara dalam talian menuntut kerjasama dan komitmen sepenuhnya dari semua pihak terutamanya melibatkan penyediaan platform pembelajaran, penyediaan bahan, pengetahuan dan kemahiran berkaitan penggunaan teknologi kerana ia akan melibatkan peranti digital di samping akses capaian internet yang berkualiti (Golzari et al., 2010). Sejajar dengan saranan yang telah dilaksanakan oleh Kementerian Pengajian Tinggi, pihak institusi pengajian awam dan swasta mula mengambil inisiatif dan strategi tertentu bagi memastikan sesi pembelajaran dapat berjalan seperti biasa melalui pembelajaran dalam talian.

Terdapat beberapa kajian awal yang telah dijalankan untuk melihat kesediaan dan cabaran yang dialami pelajar semasa berdepan dengan sesi pembelajaran dalam talian. Tidak dapat dinafikan golongan pelajar adalah antara golongan yang paling terkesan kerana mereka terpaksa beralih daripada amalan pembelajaran konvensional iaitu secara bersemuka kepada atas talian bagi memastikan proses pembelajaran sedia ada tidak terganggu terutama semasa negara terpaksa berdepan dengan impak wabak COVID-19 (Chung, Mohamed Noor \& Mathew, 2020; Amani Nawi \& Umi Hamidaton, 2020). Malahan, perubahan ini tidak hanya berlaku di Malaysia tetapi turut melibatkan negara lain seperti United Kingdom. Misalnya, University of Cambridge turut melaksanakan sesi pembelajaran secara dalam talian bagi sesi akademik 2020/2021 bagi membendung penularan pandemik ke atas para pelajar dan perubahan ini sedikit sebanyak memberi impak kepada proses pembelajaran sedia ada (Europe News, 2020).

Selain itu, menurut Tam dan El Azhar (2020), akibat daripada pandemik COVID-19 telah dianggarkan lebih 421 juta orang pelajar terjejas proses pembelajaran mereka bagi sesi pengajian semasa apabila institusi pengajian terpaksa ditutup serta merta demi menjaga keselamatan warga kerja dan golongan pelajar yang merupakan golongan berisiko terlibat dengan jangkitan. Menurut kajian yang telah dijalankan oleh Mohamed Nazul (2020), terdapat beberapa cabaran yang dihadapi oleh pelajar dalam menjalani pembelajaran dalam talian melibatkan keupayaan untuk mengadaptasi perubahan teknologi kerana ia melibatkan pembelajaran secara digital serta perubahan sikap untuk menerima amalan pembelajaran dalam talian yang dilaksanakan.

Selain itu, dalam proses pelaksanaan pembelajaran dalam talian semasa COVID-19 pelbagai pihak memainkan peranan masing-masing bagi tujuan mengurangkan jurang digital yang berlaku. Ini dapat dibuktikan apabila terdapat beberapa buah negara mengambil langkah dan inisiatif tambahan misalnya menyebarkan peranti kepada pelajar untuk meningkatkan akses ke kelas dalam talian (Wan, 2020). Misalnya, negara Finland, China dan United States memberi ruang kepada pelajar untuk mendapatkan pinjaman alat digital dari pihak sekolah bagi tujuan memudahkan pelajar mengakses platform pembelajaran dalam talian. Malah, terdapat beberapa buah syarikat swasta turut bekerjasama dalam menyumbang peranti kepada golongan pelajar yang benar-benar memerlukan.

Berdasarkan kajian-kajian terdahulu, salah satu strategi umum yang digunakan oleh responden dalam menghadapi tekanan semasa wabak adalah dengan mencari sokongan sosial (Mak et al., 2009; Main et 
al., 2011). Semasa penularan wabak COVID-19 ini, antara sokongan sosial yang paling mudah diperoleh adalah dari keluarga terdekat dan rakan-rakan. Walaupun, perhubungan antara individu ini mempunyai limitasi berikutan pelaksanaan PKP dan penjarakan fizikal, namun ia bukanlah penghalang untuk individu tersebut mendapatkan bantuan pada era digital Revolusi Industri 4.0 ini. Perkara ini lebih mudah dilakukan bagi individu yang tinggal bersama pasangan atau keluarga. Perkara ini dapat dilakukan dengan medium berbeza seperti interaksi melalui telefon, media sosial, menghantar e-mel dan sebagainya. Selain itu, sokongan sosial ini juga dapat diperoleh daripada komuniti sokongan yang diwujudkan oleh badan-badan kerajaan serta bukan kerajaan dikala wabak COVID-19 yang sedang menular dengan pantasnya. Perkhidmatan kaunseling seperti tele-kaunseling yang diwujudkan oleh kerajaan haruslah dimanfaatkan dengan sebaik mungkin oleh individu yang mengalami tekanan ini.

\section{Pendekatan Teori Kesejahteraan (Psychological Well-being Theory-PWB)}

Teori Kesejahteraan Psikologi atau Psychological Well-being (PWB) telah diperkenalkan oleh Carol Ryff pada tahun 1989. Ryff menghasilkan enam dimensi yang disebut sebagai kesejahteraan psikologi. Enam dimensi tersebut adalah autonomi (autonomy), penguasaan persekitaran (enviromental mastery), pertumbuhan kendiri (personal growth), hubungan positif dengan orang lain (positive relations with others), tujuan hidup (purpose in life) dan penerimaan diri (self-acceptance).

\section{i. Autonomi (Autonomy)}

Autonomi dimaksudkan kemampuan individu untuk bebas namun tetap mampu untuk mengatur hidup dan tingkah lakunya dan ia juga mampu untuk mempertimbangkan pilihan yang negatif dan yang positif. Individu yang memiliki autonomi yang tinggi mampu untuk menentukan hala tuju dirinya sendiri (self-determination), mengatur tingkah laku sendiri, mempunyai kemampuan untuk berdikari, menahan dari tekanan sosial, dapat menilai diri sendiri, dan dapat membuat keputusan tanpa campur tangan orang lain. Sebaliknya, individu yang rendah dalam dimensi autonomi akan memperhatikan dan meletakkan harapan dan penilaian berdasarkan orang lain, bergantung kepada orang lain untuk membuat keputusan penting, dan mudah dipengaruhi oleh tekanan sosial untuk berfikir dan berkelakuan dengan cara tertentu (Ryff, 1995).

\section{ii. Penguasaan Persekitaran (Environmental Mastery)}

Penguasaan persekitaran adalah kemampuan individu mengatur lingkungan persekitarannya, mengambil peluang yang wujud, mencipta, dan mengawal persekitaran agar sesuai dengan keperluan mereka. Ryff mendefinisikan penguasaan persekitaran sebagai kemampuan individu untuk mencipta peluang merealisasikan potensinya dan memenuhi keperluannya. Individu yang mempunyai penguasaan persekitaran yang tinggi adalah individu yang mampu menggunakan peluang dan mencipta peluang untuk mengembangkan atau memajukan dirinya. Sebaliknya, individu yang tidak dapat mengawal persekitarannya akan kehilangan peluang yang ada sehingga potensinya tidak dapat berkembang.

\section{iii. Pertumbuhan Kendiri (Personal Growth)}

Pertumbuhan kendiri ditakrifkan sebagai keupayaan individu untuk terus mengembangkan potensi diri supaya dapat menjadi individu yang berfungsi sepenuhnya. Individu yang memiliki nilai yang tinggi dalam dimensi ini dicirikan sebagai individu yang mempunyai hasrat, perasaan dan keinginan yang terus berkembang, suka akan pengalaman yang baru, menyedari kelebihan yang ada pada dirinya dan terus menerus dalam melakukan improvisasi dalam diri. Sebaliknya individu yang mempunyai nilai yang rendah dalam dimensi ini merasakan diri mereka lemah, tidak melihat peningkatan dan perkembangan diri, merasa bosan dan kehilangan minat dalam kehidupan mereka, serta merasa tidak dapat mengembangkan sikap dan tingkah laku yang baik (Ryff, 1995).

iv. Hubungan Positif dengan Orang Lain (Positive Relations with Others). 
Hubungan positif yang dimaksudkan adalah kemampuan individu menjalin hubungan baik dengan orang lain di sekelilingnya. Individu yang tinggi dalam dimensi ini dicirikan oleh hubungan mesra dan baik dengan persekitarannya, memilih untuk mengeratkan hubungan baik dan mempercayai orang lain. Selain itu, individu ini juga mementingkan kesejahteraan orang lain, dapat menunjukkan rasa empati, kasih sayang dan memahami prinsip-prinsip memberi dan menerima dalam hubungan interpersonal. Sebaliknya, individu yang rendah dalam dimensi hubungan positif dengan orang lain dilihat melalui pengasingan diri, terpencil dan merasa kecewa dalam menjalinkan hubungan interpersonal serta tidak mahu berkompromi dalam menjaga hubungan dengan orang lain (Ryff, 1995).

\section{v. Tujuan hidup (purpose of life)}

Tujuan hidup bermaksud individu mencari makna dan tujuan dalam kehidupan mereka sendiri untuk mencapai kesihatan mental dan juga proses perkembangan yang matang. Dalam dimensi ini juga menjelaskan kemampuan individu untuk menentukan arah dalam hidup dan juga untuk memperlihatkan serta menyusun hala tuju dalam hidupnya (Ryff \& Singer, 2008). Individu yang mempunyai pemahaman yang jelas mengenai tujuan dan arah hidupnya akan berasa yakin dan merasakan bahawa pengalaman masa lalu dan masa kini yang dilalui mempunyai makna. Individu yang tinggi dalam dimensi ini adalah individu yang mempunyai tujuan dan hala tuju dalam hidup, merasakan makna dalam kehidupan mereka sekarang dan juga apa yang telah mereka jalani, mempunyai kepercayaan dalam mencapai objektif hidup mereka. Sebaliknya, individu yang rendah dalam dimensi (matlamat hidup) akan kehilangan arah dan makna dalam kehidupan, hala tuju dan aspirasi yang tidak jelas, tidak melihat pengajaran yang terkandung dari peristiwa lepas dan tidak mempunyai harapan atau kepercayaan dalam kehidupan (Ryff, 1995).

\section{vi. Penerimaan Diri (Self-Acceptance)}

Penerimaan diri adalah kemampuan seseorang untuk menerima dirinya secara keseluruhan sama ada pada masa sekarang dan juga masa lalu. Ryff mendefinisikan penerimaan diri sebagai sikap atau pandangan positif terhadap diri sendiri. Individu yang menilai diri mereka secara positif adalah individu yang memahami dan menerima pelbagai aspek diri mereka termasuk sifat baik dan buruk, berfungsi dengan optimum dan mempunyai sikap positif terhadap kehidupan yang mereka jalani. Sebaliknya, individu yang menilai diri mereka secara negatif menunjukkan rasa tidak puas hati terhadap keadaan mereka, merasa kecewa dengan apa yang telah berlaku dalam kehidupan mereka yang lalu, mempunyai masalah dengan kualiti peribadinya dan ingin berbeza dengan diri mereka sendiri atau tidak menerima diri mereka sendiri (Ryff, 1995).

Berdasarkan penjelasan di atas, dapat disimpulkan bahawa kesejahteraan psikologi adalah perasaan individu yang gembira dan berpuas hati dengan hidupnya. Bahkan, kesejahteraan kendiri ialah apabila individu merasakan dirinya kompeten, bebas, menerima dirinya, mempunyai tujuan hidup, pertumbuhan peribadi dan hubungan positif dengan orang lain.

\section{Teori TransaksionalTekanan}

Richard Lazarus dan Susan Folkman adalah tokoh terkenal dalam mengembangkan model transaksional. Teori tekanan dikemukakan oleh Lazarus dan Folkman (1984) menyatakan bahawa tekanan adalah hubungan antara individu dan persekitarannya yang dinilai oleh seseorang sebagai ketidakupayaan untuk menghadapi situasi yang membahayakan atau mengancam kesihatan diri. Teori Tekanan Transaksional oleh Lazarus dan Folkman (1984) ini juga menyatakan bahawa tekanan yang dihasilkan disebabkan oleh transaksi antara pelajar dan persekitaran kerana menurut teori ini, tekanan adalah akibat dari transaksi antara individu dan persekitarannya. Seseorang akan mengalami tekanan apabila berhadapan dengan situasi yang mengganggu pemikiran atau kegiatannya. Tekanan juga merujuk kepada kemunculan sesuatu yang memberi impak psikologi terhadap seseorang akibat daripada masalah yang nyata (Yaacob et al., 2013) atau disebabkan oleh faktor-faktor yang kuat daripada persekitaran (Yusof \& Azman, 2013). Dalam konteks tekanan akademik juga, Thawabieh dan Qaisy (2012) menjelaskan bahawa pelajar mengalami tekanan akademik hasil daripada peperiksaan, tugasan dan keperluan lain di universiti yang mungkin melebihi matlamat mereka. Justeru dalam 
mendepani perubahan sistem PdP semasa pandemik COVID-19 yang berlaku ini telah memberi implikasi besar kepada kaedah pengajaran sekali gus dilihat mampu mencetuskan tekanan kepada pelajar.

\section{Metod Kajian}

Kajian ini merupakan kajian kualitatif dengan menggunakan pendekatan content analysis (analisis kandungan) di mana pengkajian menggunakan sumber dari jurnal, majalah, surat khabar, buletin dan sebagainya untuk mengolah kandungan artikel (Fraenkel \& Wallen, 1993). Di dalam menggunakan kaedah analisis kandungan ini, ia perlu dimulakan dengan menyediakan latar belakang atau menjelaskan teori kajian. Ini bermakna penulis perlu mengetahui aspek yang hendak dikaji dengan memfokuskan kepada kandungan untuk diperbahasakan. Ini dilakukan dengan membaca, menganalisis dan menstrukturkan kandungan yang relevan mengikut topik kajian literatur. Seterusnya, hubung kait antara cadangan atau topik kajian literatur dengan penyelidikan yang telah dilakukan dicari. Hubung kait juga perlu dilakukan terhadap sumber tidak rasmi seperti surat khabar, majalah dan buletin. Kemudian bahan ini telah diintegrasikan dengan hasil kajian iaitu kandungan yang telah dihubung kait untuk diadunkan dengan pengetahuan sendiri. Proses ini juga memerlukan analisis kritikal sebelum melakukan proses terakhir di mana laporan penuh disediakan dengan menggabungkan bahan-bahan berhubung tekanan akademik semasa COVID-19 yang dirujuk serta pengetahuan sedia ada. Gambarajah 1 di bawah menunjukkan proses analisis kandungan yang diguna pakai untuk menghasilkan penulisan ilmiah ini.

Rajah 1: Proses analisis kandungan

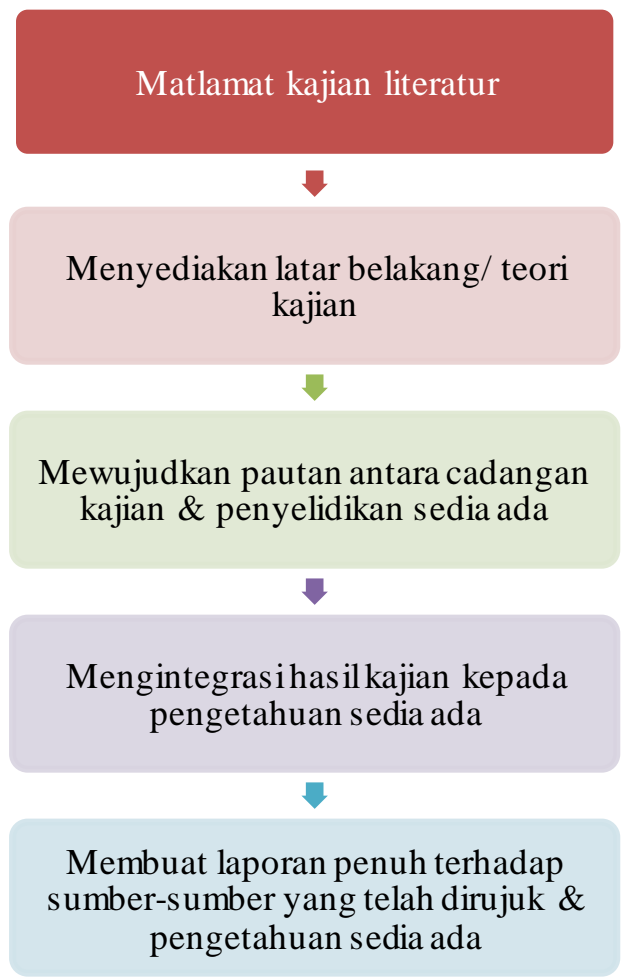

Sumber: Adaptasi dari Kumar (2011) dan Rashidi et al. (2014) 


\section{Hasil Kajian dan Perbincangan Kajian}

\section{Cabaran dan Tekanan Pelajar Semasa Norma Baharu}

\section{Penyesuaian Kendiri}

Secara umumnya, setiap benda hidup di muka bumi ini melalui proses penyesuaian dan adaptasi untuk memenuhi keperluan, mencapai kesejahteraan diri dan keamanan sejagat. Walaupun istilah penyesuaian dan adaptasi ini mempunyai perbezaan, namun sering kali digunakan dalam menggambarkan keadaan yang sama disebabkan wujud pertindihan dalam kedua-dua takrif tersebut. Penyesuaian juga membantu makhluk untuk mencapai keperluan diri dan persekitaran untuk kelangsungan hidup (survival). Oleh itu, dapat difahami bahawa penyesuaian kendiri merujuk kepada proses seseorang beradaptasi dengan diri serta persekitaran dalam kehidupan bagi mencapai keperluan dan matlamat yang diharapkan.

Berdepan dengan situasi pada masa kini, pelbagai bentuk tekanan yang telah dihadapi oleh pelajar semasa pandemik COVID-19. Sebilangan besar pelajar juga kurang bersedia menghadapi norma baharu seperti pembelajaran dalam talian. Hal ini kerana, mereka telah terbiasa dengan pembelajaran secara bersemuka. Kewujudan norma baharu ini memberi kesan yang buruk terhadap aspek psikologikal sekiranya individu gagal membuat penyesuaian kendiri terhadap perubahan drastik tersebut (Rashid, 2020). Seperti yang kita tahu, untuk menghadapi pembelajaran dalam talian pelajar perlu bersedia dengan alat komunikasi seperti telefon, komputer atau komputer riba. Jika sebelum ini pelajar belajar secara bersemuka akan tetapi pada waktu ini pembelajaran secara maya mula mengambil alih kaedah pembelajaran konvensional melalui pelbagai pendekatan sama ada pembelajaran secara bersemuka (synchronous learning) ataupun secara tidak bersemuka (asynchronous learning). Antara alatan bantu mengajar (learning tools), yang digunakan perlulah bersesuaian mengikut keperluan pembelajaran misalnya Microsoft Teams, Facebook Live, Telegram, Zoom atau Google Classroom (Chung et al., 2020). Hal ini juga memerlukan pelajar menguasai aplikasi tersebut. Namun, penggunaan peranti dan aplikasi ini terkadang mencetuskan masalah (technical error) untuk pelajar akses masuk ke dalam kelas. Hal ini telah memberi tekanan kepada pelajar dalam penggunaan aplikasi yang pelbagai, baru dan kelemahan tertentu susulan darinya.

\section{Capaian Internet}

Pembelajaran dalam talian perlu menggunakan internet (Data) yang perlu dibeli untuk mengakses masuk ke dalam kelas atau mencari maklumat untuk tugasan atau kerja rumah. Menurut Fakrul (2020), belajar di luar kelas seperti dalam talian benar-benar memberi cabaran kepada pendidik apatah lagi sekiranya mengajar di luar bandar yang mempunyai masalah kepada capaian internet. Hal ini kerana, tidak semua pelajar mahupun ahli keluarga mereka mempunyai akses internet dan alat elektronik, yang merupakan halangan terbesar untuk mewujudkan kaedah pembelajaran. (Fakrul, 2020). Bahkan, tidak semua pelajar mempunyai akses rangkaian internet yang baik di kediaman mereka, terutamanya di kampung dan pedalaman (Anuar Ahmad, 2020). Pelajar juga perlu memilih jenis talian (telco) yang mempunyai capaian internet di kawasan mereka. Bagi pelajar yang tinggal di kawasan pedalaman, agak sukar bagi mereka untuk mendapat capaian internet dengan baik dan ada juga di kawasan mereka yang tidak ada capaian internet langsung. Rentetan itu, tular pelbagai berita seperti, 'pelajar memanjat pokok untuk menjawab exam', 'pelajar jatuh jambatan semasa mencari capaian internet' dan banyak lagi isu-isu lain. Walau bagaimanapun, kekangan yang wujud dalam PdP secara dalam talian seperti masalah capaian Internet, ketiadaan peranti digital pintar serta sikap pelajar sendiri merupakan cabaran yang perlu diharungi bagi memastikan proses penyampaian ilmu diteruskan (Berita Harian, 2020).

Di samping itu, Hazwani et al., (2016) mendapati faktor prasarana amat mempengaruhi keberkesanan pembelajaran atas talian atau e-learning. Masalah teknikal yang melibatkan capaian internet, serta masalah dalam kelajuan sambungan internet menjadi isu kepada para pelajar dan pendidik. Malah, masalah ini masih lagi berlaku melainkan para pendidik menggunakan internet 
peribadi melalui capaian internet secara broadband dan hot spot (Hasliza, Siti Munira dan Zarina, 2016). Hal ini selaras dengan Dasar e-pembelajaran Negara 2.0 (DePAN 2.0) yang mana dasar ini turut memfokuskan kepada penggunaan dan penambahbaikan liputan wifi di seluruh IPT yang ditekankan dalam Fasa 2 (2016-2020) untuk 90 peratus liputan wifi dan Fasa 3 (2021-2025) dengan 100 peratus liputan wifi kepada pelajar.

\section{Pembelajaran Kendiri}

Cabaran utama dalam aspek pembelajaran kendiri adalah kelemahan dalam pengurusan masa di kalangan pelajar. Kajian-kajian lepas (Misra \& McKean, 2000; Kearns \& Gardiner, 2007) menunjukkan bahawa pengurusan masa mempunyai hubungan dengan tahap stres dalam kalangan pelajar. Pengurusan masa yang lemah akan meningkatkan tahap stres pelajar. Mereka perlu membahagikan masa antara jadual kuliah, tutorial dan tugasan. Malah, kekurangan infrastruktur di rumah juga menjadi kekangan bagi pembelajaran kendiri (Kassim, 2010). Malah, pembelajaran secara bersemuka dapat membuatkan pelajar lebih fokus berbanding pembelajaran dalam talian. Hal ini kerana, semasa pembelajaran dalam talian, pelajar berada di rumah dan bebas melakukan apa sahaja. Gangguan persekitaran di rumah juga boleh menyebabkan pelajar tidak fokus kepada PdP. Komitmen lain yang terdapat di rumah seperti membantu ibu bapa dan tanggungjawab seharian telah menyebabkan pengurusan masa pelajar menjadi tidak teratur.

Selain itu, cabaran pembelajaran kendiri juga berlaku apabila pelajar tidak mempunyai tempat yang kondusif untuk belajar. Masalah ini meliputi suasana persekitaran yang bising, tempat yang sempit serta tiada meja dan kerusi yang sesuai. Sekali gus, keadaan sebegini lebih menyukarkan pelajar untuk fokus dalam pembelajaran online ini. Pembelajaran dalam talian juga tidak membentuk disiplin belajar kerana kurang pengawasan dan pelajar cenderung bersikap sambil lewa disebabkan kurangnya pemantauan ini. Tambahan pula, tenaga pengajar juga tidak dapat mengukur kemampuan para pelajarnya kerana tidak bersemuka dan berbincang secara perseorangan. Kelemahan PdP secara dalam talian ini juga diakui Kementerian Pendidikan Malaysia (KPM) yang mendapati bahawa PdP secara dalam talian di samping belajar dari rumah kurang berkesan berbanding secara bersemuka. Hal ini dinyatakan Menteri Kanan (Pendidikan), Dr Mohd Radzi Jidin iaitu kementerian sedar terdapat kelemahan dalam pelaksanaan pembelajaran secara dalam talian yang sedang dijalani pelajar di Institusi Pengajian Tinggi (myMetro, 2020).

\section{Isu kewangan}

Bukan itu sahaja yang perlu dihadapi oleh pelajar kerana semasa pembelajaran dalam talian pelajar perlu mengeluarkan wang untuk membeli (data) internet. Rentetan itu, ia mencetuskan isu kewangan apatah lagi dalam kalangan keluarga B40. Untuk menjalani pembelajaran dalam talian, pelajar perlu mempunyai data internet yang mencukupi sekali gus menyebabkan mereka memerlukan wang untuk membeli internet (data) tersebut bagi tujuan mengakses kelas dalam talian, membuat tugasan, kerja rumah dan banyak lagi (Tamara et al., 01). Bahkan membeli internet (data) yang terdiri dari pelbagai pakej sememangnya memerlukan banyak wang. Pelajar menggunakan telefon bimbit terpaksa membeli data semasa mengakses internet. Mereka terpaksa berbelanja banyak untuk memudahkan komunikasi (Mohan, 2020). Malahan, terdapat pelajar yang melakukan kerja sambilan untuk menampung kewangan semasa belajar.

\section{Pembentukan aspek Kesejahteraan Kendiri Mendepani Tekanan Akademik Pelajar}

Pembentukan aspek kesejahteraan kendiri dilakukan melalui strategi daya tindak. Ia merujuk kepada percubaan untuk mengubah masalah yang dihadapi secara aktif dan merangkumi strategi seperti penyelesaian masalah secara langsung, mencari sokongan emosi dan membuat perancangan. Strategi daya tindak ini dapat dikategorikan dalam strategi daya tindak yang berfokus masalah. Ia merangkumi beberapa cara penyelesaian dengan mentakrifkan semula masalah bagi meminimumkan kesan tekanan yang dihadapi, seterusnya menyedari tekanan yang dialami, 
memeriksa sumber, kemudahan dan membuat perancangan untuk mengatasinya. Secara ringkas, (Lazarus \& Folkman, 1987) menyatakan bahawa strategi berfokus masalah melibatkan aspek kognitif dan ia merangkumi langkah-langkah konstruktif seseorang dalam situasi tertekan dengan cuba menghilangkan atau mengubah sumber tekanan melalui; 1) Penyelesaian masalah secara terancang; dan 2) melalui konfrontasi.

\section{Meningkatkan aspek Kesejahteraan Mental}

Ekoran dari tekanan yang pelajar hadapi semasa pandemik ini, ia telah memberi kesan kepada kesejahteraan kendiri. Keyes \& Waterman, (2003) menjelaskan bahawa antara kesejahteraan mental dan kesihatan mental merupakan dua istilah yang tidak boleh dipisahkan kerana ia mempengaruhi kesejahteraan kendiri seseorang. Oleh itu, strategi kognitif merangkumi strategi seperti penyelesaian masalah secara langsung, mencari sokongan emosi dan membuat perancangan (Lazarus \& Folkman, 1987). Dalam melaksanakan pengurusan pembelajaran kendiri, pelajar perlu kreatif dan bijak dalam mengadaptasi maklumat berkaitan pembelajaran secara 'self-paced' dan 'live online learning'. Pelajar perlu bijak dalam aspek pengurusan masa berkaitan aktiviti pembelajaran dan tugasan yang diberikan.

Struthers, Perry, dan Menec (2000) menunjukkan bahawa individu yang mempunyai keyakinan mampu menyelesaikan masalah, mendapatkan sokongan sosial dan menekankan aspek pemikiran positif apabila berhadapan dengan situasi yang sukar. Keyakinan diri adalah asas kepada pemikiran positif. Apabila seseorang itu berhadapan dengan tekanan dan masalah, usaha yang perlu dibuat adalah untuk menyelesaikan masalah dan melihat masa depan sebagai cabaran yang perlu dihadapi. Hal ini dapat meningkatkan kesejahteraan psikologi dan membuat jiwa lebih tenang (Struthers et al., 2000).

Selain itu, strategi daya tindak yang boleh dilakukan oleh pelajar yang menghadapi tekanan akademik adalah dengan melibatkan diri dalam aktiviti seperti mendengar muzik, menyanyi, bermain alat muzik, menonton televisyen, mempelajari kemahiran baru dan mengimbas memori bahagia melalui album gambar. Aktiviti ini bukan sahaja boleh dilakukan oleh individu yang mengalami tekanan malah ia turut boleh dilakukan oleh ibu bapa bersama ahli keluarga dalam mengisi waktu bersama semasa fasa kawalan pergerakan. Aktiviti-aktiviti sebegini membantu pelajar untuk melupakan pengalaman yang negatif dan pahit (Fredrickson, Tugade, Waugh, \& Larkin, 2003) dan dapat mengurangkan beban psikologi yang ditanggung akibat tekanan seharian melalui penyesuaian diri dengan situasi yang sentiasa berubah-ubah (Bonanno, Brewin, Kaniasty, \& La Greca, 2010). Di samping itu, pengurusan masa adalah aspek yang memerlukan perhatian agar kehidupan seharian pelajar tidak bosan. Pelajar perlu membuat jadual harian dengan aktivitiaktiviti yang sihat dan menyeronokkan. Selain itu, pengajian boleh diteruskan secara dalam talian (online) dan pelajar boleh membuat jadual waktu belajar dan mengulang kaji pelajaran. Perbincangan serta sesi diskusi boleh diatur bersama rakan-rakan dan pensyarah melalui perantaraan media seperti e-mel, WhatsApp, Skype dan lain-lain (Sherina, 2020).

\section{Meningkatkan aspek Kesejahteraan Emosi}

Wabak COVID-19 yang tersebar secara berleluasa telah mengganggu emosi kebanyakan pelajar. Rata-rata daripada mereka mengalami perasaan sedih, risau, tidak tenang, marah dan berasa bosan. Sekiranya pelajar memilih menggunakan strategi daya tindak berfokus emosi seperti makan berlebihan dan merokok, ia bukan sahaja akan menjejaskan kesihatan fizikal tetapi juga boleh menyumbang kepada tekanan emosi. Justeru, adalah penting untuk pelajar memilih strategi daya tindak yang bersesuaian dalam berhadapan dengan apa jua bentuk tekanan. Hal ini kerana, strategi daya tindak berfokus emosi boleh memberi kesan negatif terhadap kesejahteraan psikologi (Penley, Tomaka, \& Wiebe, 2002).

Strategi daya tindak berfokus emosi terdiri daripada percubaan atau usaha yang boleh dilakukan oleh pelajar untuk mengurangkan emosi negatif yang disebabkan situasi tekanan dalam PdP. Tekanan boleh timbul dalam pelbagai bentuk dan pelajar juga bebas memilih sama ada menyalahkan diri sendiri dan mengasingkan diri (Lazarus \& Folkman, 1987). Namun demikian, 
menyalahkan diri sendiri atau kritik diri merupakan strategi daya tindak negatif dan tidak sesuai digunakan dalam mengharungi cabaran hidup kerana boleh menyumbang kepada kemurungan dan tekanan yang tinggi (Kapsou et al., 2010). Dalam kajian Melissa Edora Sanu \& Balan Rathakrishnan (2018), didapati bahawa kritik diri berhubung secara negatif dengan kesejahteraan psikologi.

Strategi daya tindak berfokus emosi mempunyai kelebihan untuk mengurangkan tahap tekanan apabila pelajar boleh mencari cara untuk berhadapan dengan tekanan dengan menerima sahaja apa yang berlaku. Contohnya, menangis kadangkala merupakan sesuatu yang diperlukan untuk memberikan kelegaan sementara. Oleh itu, kedua-dua bentuk strategi daya tindak (berfokus masalah dan emosi) adalah penting dan mempunyai fungsi adaptif. Apa yang lebih penting adalah perlunya keseimbangan antara kedua-dua strategi daya tindak.

\section{Meningkatkan aspek Kesejahteraan SpiritualKeagamaan}

Aspek keagamaan dan spiritual merupakan salah satu strategi daya tindak terhadap tekanan pelajar dalam urusan akademik mereka. Ini kerana ia berfungsi sebagai sistem orientasi yang tersedia terutama ketika tekanan itu berada di luar keupayaan pelajar untuk mengatasinya (Pargament et al., 2013). Selain itu, agama juga menyediakan suatu kerangka untuk memahami penderitaan emosi dan fizikal, sehingga mewujudkan rasa redha dalam berhadapan dengan tekanan (Wortmann, 2013). Setiap individu harus mengubah pandangan buruk terhadap wabak COVID-19 ini dan sebagai umat Islam, seseorang individu haruslah yakin kepada Allah SWT bahawa Allah akan sentiasa menolong dan memberi jalan keluar kepada setiap hambanya. Justeru, mereka haruslah sentiasa mendekatkan diri dengan Allah SWT melalui aktiviti beribadah. Ini selaras dengan agama Islam yang menekankan kepada konsep tawakal apabila berhadapan dengan musibah iaitu dengan meletakkan kembali pergantungan kepada Allah SWT.

Komponen spiritual ini juga memainkan peranan yang sangat penting apabila pelajar berhadapan dengan tekanan akademik sewaktu COVID-19. Aktiviti beribadah ini dapat dilakukan dengan cara bertadabbur al-Quran. Tadabbur ialah menghayati ayat Al-Quran untuk mencari petunjuk daripada dalil dan ayat tersebut untuk diterapkan di dalam ilmu serta amal. Tadabbur juga merupakan salah satu cara untuk mengambil hikmah dan pengajaran dari ayat-ayat Allah SWT (Al-Quran) untuk digunakan dalam kehidupan. Ia adalah perkara yang dianjurkan oleh agama. Sepertimana melalui firman Allah SWT dalam Surah Muhammad: ayat 24 yang bermaksud:

\section{"Maka apakah mereka tidak mentadabburkan al-Quran? Atau hati mereka terkunci."}

Selain itu, pelajar juga boleh mengamalkan zikir yang boleh bertindak sebagai perisai dalam memperkuatkan roh dalaman diri menghadapi tekanan akademik ini. Zikir bermaksud suatu perbuatan mengingati Allah dengan menyebut beberapa kalimah tertentu. Ia juga merujuk kepada menyebut nama Allah SWT, mengulang dan mengingati sama ada secara jelas melalui lisan dan perkataan mahupun secara sembunyi di dalam hati. Amalan berzikir perlu diterapkan dalam aktiviti seharian. Zikir-zikir ini perlu diamalkan dengan penuh keikhlasan semata-mata kerana Allah SWT serta dengan penuh keyakinan kepada-Nya iaitu dengan menghayati makna yang terkandung di dalam zikir supaya dapat memberi kesan yang positif dalam kehidupan, akhlak dan tingkah laku.

Bersolat dan berdoa juga merupakan ibadah yang tidak boleh ditinggalkan oleh setiap umat Islam. Solat merupakan tiang agama. Rasulullah SAW menjelaskan bahawa walaupun Islam adalah asal agama tetapi tanpa tiangnya sudah tentu agama ini tidak kuat dan mudah runtuh seperti rumah tidak bertiang. Dalam hadis Riwayat Al-Tirmizi, Rasulullah SAW bersabda:

"Asas segala amalan adalah Islam, tiangnya adalah solat dan puncaknya adalah jihad"

Oleh itu, persediaan spiritual termasuk sentiasa beriltizam untuk tidak meninggalkan solat dan tidak sentiasa menangguhkannya, memelihara rukun dan syarat sahnya serta bersembahyang nawafil seperti solat hajat, solat tasbih, solat syukur, solat tahajjud, solat dhuha dan sebagainya 
haruslah menjadi kebiasaan bagi orang yang ingin berjaya (Hamin, 2012). Berdoa pula dapat membantu menguatkan pergantungan seorang hamba (manusia) kepada pencipta iaitu Allah SWT. Berdoa akan mewujudkan rasa tenang dan bahagia dalam situasi wabak COVID-19 yang melanda kini. Justeru, dalam menghadapi norma baharu ini, bersolat dan berdoa adalah aktiviti yang perlu dilakukan secara konsisten dan digalakkan juga untuk memperbanyakkan solat sunat untuk mendatangkan ketenangan dan ketenteraman jiwa. Mohammmad Shatar (2005) menyatakan bahawa pengukuhan spiritual dan aspek-aspek spiritual mampu menyumbang kepada pembelajaran berkesan. Ia berkait rapat dengan aspek psikologi dan mental manusia dalam konteks kebergantungan manusia kepada Allah SWT.

\section{Meningkatkan aspek Kesejahteraan Fizikal}

Kesihatan fizikal adalah merujuk kepada sesuatu keadaan diri individu bebas daripada kesakitan, ketidakupayaan fizikal, penyakit kronik mahupun penyakit berjangkit serta ketidakselesaan tubuh badan yang memerlukan penjagaan atau perhatian daripada pakar dalam bidang perubatan (Norliah, 2017). Sekiranya pelajar berhadapan dengan tekanan akademik, terdapat banyak cara yang melibatkan strategi daya tindak tingkah laku bagi keluar dari masalah tekanan tersebut.

Komponen tingkah laku merujuk kepada aktiviti dalam bentuk tindakan dan perbuatan yang boleh dilakukan bagi mengurangkan tekanan akademik semasa wabak COVID-19. Menurut Polizzi, Lynn dan Perry (2020), terdapat pelbagai aktiviti yang boleh dijalankan oleh individu sebagai strategi daya tindak dalam menghadapi stres termasuklah individu tersebut boleh melakukan hobi dan aktiviti yang mencabar fizikal seperti mendaki gunung, menyelam, berenang dan sebagainya. Selain itu, individu yang berhadapan dengan tekanan juga boleh melakukan pelbagai aktiviti relaksasi seperti mengamalkan senaman pernafasan mendalam (deep breathing exercise), senaman regangan (stretching exercise) dan aktiviti lain seperti tarian, senamrobik dan zumba. Seterusnya aktiviti beriadah dengan meluangkan masa untuk melakukan aktiviti di luar rumah sama ada bersama keluarga dan jiran tetangga. Sekiranya pelajar melakukan aktiviti yang disukai secara sihat ia dapat mengembalikan minat dan semangat yang hilang disebabkan tekanan akademik. Beriadah juga dapat menenangkan fikiran pelajar dan meningkatkan penghasilan hormon serotonin serta endorfin yang membawa rasa gembira dan pada masa yang sama mengurangkan stres.

\section{Kesimpulan}

Tanpa kita sedari masalah COVID-19 hari ini telah mempengaruhi kesihatan mental masyarakat di Malaysia khususnya pelajar. Tekanan, kerisauan, serangan panik dan kemurungan yang dialami oleh pelajar disebabkan oleh pelbagai faktor dan punca stres. Hal ini sangat membimbangkan jika dibiarkan berlarutan. Contoh yang boleh diambil ialah pelajar yang tinggal di Universiti sepanjang berlangsungnya Perintah Kawalan Pergerakan (PKP). Terdapat pelajar yang tidak sempat pulang ke rumah semasa PKP dilaksanakan dan terpaksa berkurung dalam jangka masa yang lama tanpa sokongan keluarga. Hal ini juga mencetuskan tekanan dan berisiko untuk mengalami masalah kesihatan mental jika tidak dirawat dengan baik. Malah, pelajar juga perlu berdepan dengan norma baharu serta beradaptasi dengan keadaan sekeliling termasuklah dalam lingkungan PdP. Jika sebelum ini pelajar dapat belajar secara bersemuka. Akan tetapi, pandemik COVID-19 telah mengubah segalanya. Dalam keadaan ini, penyesuaian kendiri dan strategi daya tindak yang betul membantu pelajar menghadapinya.

Selain itu, penutupan institusi pengajian di negara berikutan pandemik COVID-19 yang melanda telah memberi kesan tertentu terhadap struktur PdP iaitu dari kaedah secara langsung telah beralih kepada PdP secara dalam talian sepenuhnya. Sehubungan itu para pelajar di negara ini telah berdepan dengan bentuk (mode) pengajian yang berbeza iaitu pengajaran dan pembelajaran dalam talian selari dengan Revolusi 4.0 melalui penggunaan jaringan internet dan aplikasi digital. Justeru itu, semua pihak perlu mempersiapkan diri bagi mengharungi norma baru melalui kaedah pembelajaran dalam talian secara menyeluruh demi memastikan kelangsungan proses pembelajaran berjalan dengan lancar. Pengajaran dan pembelajaran atas talian perlu dimanfaatkan sepenuhnya bagi memastikan tumpuan untuk belajar 
DOI: https://doi.org/10.47405/mjssh.v5i12.594

tidak terjejas walaupun pelbagai cabaran bakal dihadapi di masa akan datang. Para pelajar perlu bersedia mengadaptasi amalan yang berbeza daripada cara dan kaedah yang telah dilalui sebelum ini yang melibatkan kaedah pembelajaran secara bersemuka.

\section{Penghargaan}

Sekalung penghargaan ditujukan kepada Universiti Sains Islam Malaysia atas pembiayaan geran penyelidikan yang bertajuk "Faktor Yang Mempengaruhi Kesejahteraan Kendiri Terhadap Tekanan Psikologi Semasa Wabak Covid-19“(PPPI/COVID19_0120/FKP/051000/13820).

\section{Rujukan}

Amani Nawi \& Umi Hamidaton Mohd Soffian Lee. (2020). Penerimaan Pelajar Universiti Sains Islam Malaysia (USIM) terhadap Penggunaan Microsoft Teams sebagai Platform Pembelajaran-Satu Tinjauan. 3rd International Seminar on Islamic and Science. 15 October 2020, Nilai: Universiti Sains Islam Malaysia.

Amy, M. \& Bippus, S. L. (2012). Using Appraisal Theory to Predict Emotional and Coping Responses to Hurtful Messages. An International Journal on Personal Relationships, 177-190.

Basir, E. K. (2020). COVID-19: Risiko Masalah Mental, Perlu Penyelesaian Terbaik- Pakar.

Berita Harian,. (2020). Covid-19: Pendidikan Menerusi Dunia Maya Cabaran Baharu Buat Guru. Kuala Lumpur: Berita Harian Online.

Bernama. (2020). Akses internet terhad antara cabaran belajar, mengajar dalam talian. Bernama: Kuala Lumpur.

Bernama. (2020). Akses Internet Terhad Antara Cabaran Belajar, Mengajar Dalam Talian. Kuala Lumpur: Suara Sarawak.

Bernama. (2020). Covid-19: Pendidikan Menerusi Dunia Maya Cabaran Baharu Buat Guru. Kuala Lumpur: Berita Harian.

Bonanno, G. A., Brewin, C. R., Kaniasty, K., \& Greca, A. M. L (2010). Weighing the costs of disaster: Consequences, risks, and resilience in individuals, families, and communities. Psychological Science in the Public Interest, 11(1), 1-49.

Chung, E., Noor, N. M., \& Vloreen Nity Mathew. (2020). Are You Ready? An Assessment of Online Learning Readiness among University Students. International Journal of Academic Research in Progressive Education and Development, 9(1), 301-317.

Desmita (2009). Psikologi perkembangan peserta Didik: Panduan bagi orang tua dan guru dalam memahami psikologi anak usia SD, SMP dan SMA. Bandung: PT Remaja Rosdakarya.

Fraenkel, J. R., Wallen, N. E., \& Hyun, H. H. (1993). How to design and evaluate research in Education. (Vol. 7). New York: McGraw-Hill.

Fredrickson, B. L., Tugade, M. M., Waugh, C. E., \& Larkin, G. R. (2003). What good are positive emotions in crisis? A prospective study of resilience and emotions following the terrorist attacks on the United States on September 11th, 2001. Journal of Personality and Social Psychology, $84(2), 365$.

Hakimi, F. (2020). Murid Pedalaman Tiada Internet, Guru Sanggup Redah Laluan Sukar Hantar Bahan Pembelajaran. Sinarplus.

Hasliza Hashim, Siti Munira Mohd Nasri, \& Zarina Mustafa. (2016). Cabaran yang dihadapi oleh guru dalam pelaksanaan persekitaran pembelajaran maya frog di bilik darjah. Asia Pacific Journal of Educators and Education, 31, 115-129.

Hazwani Mohd Najib, Noor Raudhiah Abu Bakar, \& Norziah Othman. (2016). E-pembelajaran dalam kalangan pelajar di institusi pengajian tinggi. Proceeding of the $3 \mathrm{rd}$ International Conference on Management \& Muamalah, 1(1), 74-82.

JKP Malaysia. (2020). Cabaran Pembelajaran Online - Cadangan Mengatasinya.

Kapsou, M., Panayiotou, G., Kokkinos, C. M. \& Demetriou, A. G. (2010). Dimensionality of coping: an empirical contribution to the construct validation of the brief-COPE with a Greek-speaking sample. Journal of health psychology, 15(2), 215-229. https://doi.org/10.1177/1359105309346516 
DOI: https://doi.org/10.47405/mjssh.v5i12.594

Kearns, H. \& Gardiner, M. (2007). Is it time well spent? The relationship between time management behaviors, perceived effectiveness and work-related moral and distress in a university context. Higher Education Research and Development, 26(2): 235-247.

Lasemang, N. b. (2017). Kesihatan Fizikal dan Mental. ResearchGate, 1-10.

Lazarus, R. S., \& Folkman, S. (1987). Transactional theory and research on emotions and coping. European Journal of Personality, 1, 141-169.

Lazarus, R. \& Folkman, S. (1984) Stress, Appraisal, and Coping, Springer Publishing Company, New York.

Lazarus, R.S. (1966). Psychological Stress and the Coping Process. McGraw-Hill, New York.

Lopez, F. G., Mauricio, A. M., Gormley, B., Simko T., \& Berger E. (2001). Adult attachment orientations and college student distress: The mediating role of coping styles. Journal of Counseling and Development, 79(4), 459-464.

Main A, Zhou Q, Ma Y, Luecken LJ, Liu X. (2011). Relations of SARS-related stressors and coping to Chinese college students' psychological adjustment during the 2003 Beijing SARS epidemic. $J$ Couns Psychol, 58, 410-23.

Mak W.W., Law R.W., Woo J., Cheung F.M., \& Lee D. (2009). Social support and psychological adjustment to SARS: the mediating role of self-care self-efficacy. Psychol Health, 24, 161-174.

Mamat, N. S. (2020). COVID-19: Cabaran emosi, mental di tengah pandemik dan cara menanganinya AWANI.

Md Daud Ismail, N. S. (2016). Pembelajaran-e, Tekanan dan Komitmen Belajar dalam Kalangan Pelajar Sains Sosial di Universiti Kebangsaan Malaysia. Jurnal Personalia Pelajar, 79-91.

Melissa Edora Sanu \& Balan Rathakrishnan. (2018). Influence of Action Strategies on the Educational Well-being of Poor Students in Rural Sabah. Malaysian Institute for Youth Development Research, 1-17.

Misra, R., \& McKean, M. (2000). College students' academic stress and its relation to their anxiety, time management, and leisure satisfaction. American Journal of Health Studies, 16(1), 41-51.

Mohan, R. (2020). Covid-19 Ubah Pengajaran Dan Pembelajaran Dari Rumah. Berita Harian.

Mohd Arif Johari \& Sa'odah Ahmad. (2019). Persepsi Tekanan Akademik dan Kesejahteraan Diri di dalam Kalangan Pelajar Universiti di Serdang, Selangor. Journal of Social Sciences, 5(1), 24-36.

Mohd Nazul Ismail. (2020). Cabaran Kepimpinan dalam Pengurusan Pembelajaran Digital. Jurnal Refleksi Kepimpinan, 3, 20-24.

Mohammad Arif Bin Johari, S. A. (2019). Persepsi tekanan akademik dan kesejahteraan diri di dalam kalangan pelajar universiti di Serdang, Selangor. Journal of Social Science (EJOSS), 24-36.

MyHealth. (2006). Langkah Mencapai Kesihatan Mental yang Baik.

MyHealth. (2020). Cara Mengawal Stres.

Norazila Mat, N. I. (2020). Hubungan Antara Beban Kerja, Faktor Peribadi, Dan Pembelajaran-E Terhadap Tahap Tekanan Di Kalangan Gen-Y. Jurnal Personalia Pelajar, 23-25.

Norhana Ahad, M. F. (2020). Analisis Faktor Tekanan Yang Mempengaruhi Pelajar Kolej Komuniti Negeri Johor Ketika Perintah Kawalan Pergerakan. Jurnal Dunia Pendidikan, 150-172.

Nur Hamizah Hj Ramli, Masoumeh Alavi Seyed Abolghasem Mehrinezhad \& Atefeh Ahmadi. (2019). Academic Stress and Self-Regulation among University Students in Malaysia. Mediator Role of Mindfulness. 1-9.

Pargament, K.I., Falb, K., Ano, G., \& Wachholtz, A.B. (2013). The Religious Dimension of Coping: Advances in Theory, Research, and Practice. In R. Paloutzian \& C. Park (eds) The Handbook of the Psychology of Religion, (2nd ed.) (pp.560-580). New York: Guilford Press.

Penley, J. A., Tomaka, J., \& Wiebe, J. S. (2002). The association of coping to physical and psychological health outcomes: A meta-analytic review. Journal of Behavioral Medicine, 25, 551-603.

Polizzi, C., Lynn, S.J., Perry, A. (2020). Stress and Coping in the Time of COVID-19: Pathways to Resilience and Recovery. Clinical Neuropsychiatry, 17(2), 59-62.

Prabowo, A. (2017). Gratitude Dan Psychological Wellbeing Pada Remaja. Jurnal Ilmiah Psikologi Terapan, 260-268.

Ramdhani, D. R. (2020). Adaptasi Bahasa dan Budaya Skala Psychological Well-Being. 254-268.

Rashid Aziz. (2020). Wabak COVID-19: Penyesuaian Kendiri terhadap Norma Baharu. Capaian pada 1 Oktober 2020 dari, https://www.usim.edu.my/ms/berita/in-our-words-ms/wabak-covid-19penyesuaian-kendiri-terhadap-norma-baharu/ 
DOI: https://doi.org/10.47405/mjssh.v5i12.594

Ryff, C. D. (2015). Psychological Well-Being Revisited: Advances in Science and Practice. Jurnal $N C B I$.

Salasiah Hanin Hamjah, E. A. (2012). Perkaitan Amalan Spiritual dengan Pencapaian Akademik Pelajar. 51-60.

Sheela Sundarasen, K. C. (2020). Psychological Impact of COVID-19 and Lockdown among University Students in Malaysia: Implications and Policy Recommendations. International Journal of Environmental Research and Public Health, 1-13.

Sidik, P. D. (2020). Kesihatan Mental Pelajar Institut Pengajian Tinggi Sepanjang Perintah Kawalan Pergerakan (PKP). UPM.

Sri Nurhayati Selian, Fonny Dameati Hutagalung, Noor Aishah Rosli. (2020). Pengaruh Stres Akademik, Daya Tindak Dan Adaptasi Sosial Budaya Terhadap Kesejahteraan Psikologi Pelajar Universiti. Jurnal Kepimpinan Pendidikan, 7(2), 36-57.

Suyantob, M. A. (2017). Pendekatan Keselamatan dan Kesejahteraan Pelajar untuk Sekolah-Sekolah di Malaysia. Management Research Journal, 139-157.

Tam, G. \& El-Azhar, D. (2020). 3 ways the coronavirus pandemic could reshape education. The World Economic Forum COVID Action Platform. Dicapai pada 20 November 2020 daripada https://www.weforum.org/agenda/2020/03/3-ways-coronavirus-is-reshaping-education-and-whatchanges-might-be-here-to-stay/

Tamara, B. B., Matt, H., \& Eleanor, L. (2012). The Costs of Online Learning. In Education Reform For The Digital Era. Thomas B. Fordham Institute. Washington.

Teori Stres: Stimulus, R. d. (2016). Nasib Tua Lumban Gaol. Buletin Psikologi, 1-11.

Wilks, S. E. (2008). Resilience amid Academic Stress: The Moderating Impact of Social Support among Social Work Students. Advances in Social Work, 106-125.

Wortmann, J. (2013). Religious Coping. In: Gellman M.D., Turner J.R. (eds) Encyclopedia of 2Behavioral Medicine. New York: Springer. 